|EDITORIAL|

\title{
Comunicação e Saúde na Revista Brasileira de Pesquisa em Saúde
}

\author{
Communication and Health in the Brazilian Journal of Health \\ Research
}

Janine Cardoso ${ }^{1}$

${ }^{1}$ Fundação Oswaldo Cruz. Rio de Janeiro/RJ, Brasil

Já há alguns anos é sensível, em periódicos e eventos científicos da área, a intensificação da produção sobre comunicação e saúde por parte de pesquisadores da saúde coletiva da Universidade Federal do Espírito Santo. Essa presença expressa a abertura de linhas próprias de investigação, voltadas para a análise de diferentes doenças, articulando informações técnicas e a cobertura midiática; a ampliação de redes de parcerias e acordos de cooperação técnico-científica, como o que mantém com o Instituto de Comunicação e Informação Científica e Tecnológica em Saúde (ICICT), da Fundação Oswaldo Cruz. A chamada para o número temático da Revista Brasileira de Pesquisa em Saúde demonstra que a disposição continua e que se busca ampliar o debate com pesquisadores de outras instituições do país.

Os artigos aqui reunidos expressam a variedade de objetos empíricos e abordagens teóricas e metodológicas que caracterizam a produção na interface da comunicação e saúde. Como o(a) leitor(a) perceberá, destaca-se o predomínio do jornalismo impresso nos quinze trabalhos. A boa surpresa é que ao lado de diários muito estudados, como a Folha de S. Paulo, vários textos privilegiam jornais de importância local ou regional. Também é marcante a opção metodológica pela análise de conteúdo, embora sejam variadas as perspectivas teóricas dos autores que a mobilizam, das mais críticas, inspiradas nos autores da Escola de Frankfurt, às mais confiantes quanto ao seu potencial educativo e mobilizador em prol do interesse público, em geral, e da saúde pública, em particular. Também é notável a eleição do método do Discurso do Sujeito Coletivo para análise dos textos (não só) jornalísticos.

Nesse bloco, dois trabalhos abordam a produção noticiosa sobre o Sistema Único de Saúde (SUS) de forma ampla. Cavalcante e Lerner ${ }^{1}$, em Duas faces do mesmo Sistema? Um estudo dos sentidos do Sistema Único de Saúde no jornal Diário do Nordeste, tomam o jornalismo como prática sócio-discursiva e analisam os textos com o referencial da Semiologia dos Discursos Sociais. Concluem que há muitas críticas, ligadas à precariedades e ausências, principalmente de pessoal e tecnologias de ponta, contraponto pelo qual se valoriza os serviços privados. Mas também identificam espaços para o reconhecimento do SUS, relacionados a determinados contextos sociais, no caso, modulado pela relação do jornal com o governo estadual e à manutenção de sua própria imagem como defensor do interesse público. A saúde e o Sistema Único de Saúde nos bastidores da imprensa: o que os jornalistas têm a nos dižer?, de Silva-Mascarelo et al. ${ }^{2}$, teve como principal objetivo analisar a percepção dos próprios construtores da notícia sobre seu trabalho e as condições em que é realizado. As 
entrevistas, contudo, foram precedidas na análise da cobertura de saúde e sobre o SUS realizadas pelos dois jornais do Espirito Santo nos quais trabalham os entrevistados, $A$ Tribuna e $A$ Gazeta.

Outros artigos abordam questões mais específicas. Análise qualitativa de notícias veiculadas na mídia impressa sobre dieta alimentar e saúde bucal, de Novas et al. ${ }^{3}$, utiliza a análise de conteúdo nas matérias dos jornais capixabas Tribuna e $A$ Gaz̧eta, entre 2004 e 2009. Suas conclusões destacam a visão fragmentada, com ênfase na estética, em algumas doenças e procedimentos, em detrimento de uma perspectiva mais ampla do indivíduo e da promoção da saúde. Em Sintomas, tratamento e diagnóstico: a dengue na mídia impressa durante primeira epidemia em Ribeirão Preto, São Paulo, Villela ${ }^{4}$ toma para a análise a produção noticiosa de jornais e revistas de grande circulação nacional e outras de importância local. Utilizando o método do Discurso do Sujeito Coletivo, "cada notícia foi considerada um sujeito a ser entrevistado", em busca das representações sociais aí veiculadas. Entre seus achados, a pequena parcela de matérias dedicada aos sintomas, diagnóstico e, principalmente, ao tratamento da doença, que "inclui em seu contexto as recomendações essenciais para promoção da saúde à população". Ciclismo e saúde: as matérias sobre bicicleta veiculadas em um jornal de grande circulação no Espírito Santo, de Tavares et al. ${ }^{5}$, realiza um mapeamento descritivo das características das matérias sobre o tema no jornal $A$ Gazeta, em 2014, e identifica sua vinculação prioritária à questão da mobilidade urbana. Apesar da pequena associação com a promoção da saúde, o interesse revelado na pauta jornalística e suas interfaces com o planejamento urbano demonstram o potencial a ser explorado pelas políticas intersetoriais relevantes para a saúde. O jornal Folha de S. Paulo no contexto das indústrias culturais e midiáticas: um olhar para as manchetes sobre o Programa Mais Médicos, escrito por Emerich et al. ${ }^{6}$, também utiliza a análise de conteúdo para o material reunido durante seis meses de 2013. Com o referencial das indústrias culturais e midiáticas, destacam que as manchetes, embora digam respeito a fatos da atualidade, são atravessadas pelos interesses políticos, ideológicos e mercadológica da empresa de comunicação. Constatam que entre os vários componentes do Programa, foi o componente "provisão emergencial de médicos" que obteve maior espaço no jornal, juntamente com a dimensão política, fortemente influenciada pela proximidade das eleições. Coqueiro et al. ${ }^{7}$, apresentam um artigo de caráter metodológico, Diabetes mellitus na mídia impressa: uma proposta de protocolo de coleta e classificação de dados para pesquisa. Com base em pesquisa documental sobre esta importante doença "de longa duração" e também em outros protocolos de coleta e classificação da produção jornalística, são apresentados os resultados de um estudo piloto do sistema proposto para os pesquisadores da área.

Vários artigos desse bloco guardam relação com o Observatório de Saúde na Mídia - Regional Espírito Santo, cuja configuração e experiência é relatada em artigo de Cavaca et al. ${ }^{8}$. O texto destaca a natureza e desafios interdisciplinares que caracterizam a iniciativa, ampliados na proposta de articular comunicação e saúde coletiva, pesquisa e formação, da graduação a pós-graduação.

Ainda no campo midiático, o artigo Zikea e publicidade: reflexões sobre comunicação de risco e emergência em saúde na perspectiva das Indústrias Culturais e Midiáticas, de Nacif, Emmerich e Rebouças ${ }^{9}$, efetua pesquisa documental sobre as diretrizes que orientaram as campanhas publicitárias do Ministério da Saúde e da Secretaria Estadual do Espírito Santo contra a zika, incluindo os gastos e sua distribuição entre os diferentes meios de comunicação. Suas conclusões apontam para a permanência de um modelo de comunicação ainda distante dos preceitos do SUS e para a necessidade de uma Política de Comunicação e Saúde no Brasil, que inclua a democratização e pluralidade dos meios de comunicação, como vem sendo vocalizado nas conferências nacionais de saúde.

Também no âmbito do SUS, Barros et al. ${ }^{10}$ estão interessados nas concepções dos agentes comunitários de saúde sobre alimentação, em especial em suas percepções sobre a produção midiática sobre o tema, suas relações com a prevenção de doenças específicas ou com a promoção da saúde, compreendida de forma mais ampla, em suas relações as condições de vida da população. Os resultados obtidos em oficinas realizadas com esses profissionais de três unidades básicas de saúde do Rio de Janeiro são discutidos em Alimentação saudável na mídia de massa e promoção da saúde: percepçôes sociais de Agentes Comunitários. De autoria de Trindade, Spinielli e Moreira1 ${ }^{11}$, Modelos da Comunicação no Processo de Humanização do Parto e Nascimento em uma Maternidade de Mato Grosso, analisou as relações interpessoais entre gestores, profissionais de saúde e parturientes, tendo como questão central as dimensões comunicativas do processo de humanização da atenção. Entre os achados da pesquisa, o artigo destaca, na relação com as mulheres, tanto uma relação de escuta e acolhimento, quanto a permanência de seu oposto, a ignorar medos, dores e angústias.

Rev. Bras. Pesq. Saúde, Vitória, 20(2): 4-7, abr-jun, 2018 |5 
Reunimos no último bloco quatro trabalhos, que têm objetos, metodologias e contextos bastante diferentes. Contudo, o que nos permite aglutiná-los é a ênfase comum no reconhecimento do outro, no seu direito à saúde e à comunicação como inescapável às estratégias comunicacionais, ou educacionais, comprometidas com a democracia e o SUS.

Documentário e cinedebate como estratégia de pesquisa-ação em saúde: comunicando perigos, construindo saberes, promovendo saúde, de Santos, Gurgel e Augusto ${ }^{12}$, apresenta resultados parciais de uma pesquisa de doutorado sobre o que a expansão do Complexo Industrial Portuário de Suape, em Pernambuco, tem representado para o ambiente e saúde da população daquela região. A produção de um documentário foi utilizada "como recurso de construção de dados de pesquisa e como procedimento metodológico para discussão e validação mediante a realização de cinedebates como forma de apreensão e reconhecimento do mundo a partir das representações sociais”. As autoras ressaltam os vínculos dos debates com a promoção da saúde, que não pode prescindir da participação, autonomia, empoderamento e construção de saberes de indivíduos e comunidades. Ao revelar conflitos e injustiças ambientais, o estudo destaca a ampliação das questões que devem ser incorporadas na luta pela saúde e pelo SUS no cuidado da população daquele território.

Comunicação e saúde: abordagens e experiências da TV Ufes, de Souza e Rocha ${ }^{13}$, coloca sob análise o conteúdo informativo sobre saúde, produzido pela TV Ufes após sua reestruturação, em 2012, quando ficou claro seu caráter de comunicação pública. As autoras logo se depararam com a necessidade de definir o conceito de saúde e perceberam que a tarefa nada tinha de "trivial", por se tratar de uma construção histórica, um debate em aberto e com interfaces plásticas e movediças. O objetivo então passou a ser identificar o próprio conceito de saúde presente nos programas. Concluem que os programas se afastam da visão biológica restrita e assumem o conceito ampliado de saúde, ao transitar pela prevenção de doença, serviços, promoção da saúde, direitos humanos, temas de ciência e tecnologia, abordando as múltiplas faces da saúde como direito de cidadania.

O portfólio na formação em saúde: limites e possibilidades em uma experiência de educação à distância, de Costa et al. ${ }^{14}$, discute o portfólio como dispositivo pedagógico de interação virtual, para fins de formação e avaliação, a partir de uma experiência no âmbito da Coordenação de Educação a Distância da Escola Nacional de Saúde Pública Sergio Arouca, da Fundação Oswaldo Cruz. Utilizando o método do Discurso do Sujeito Coletivo, seus resultados enfatizam as potencialidades para a construção compartilhada dos conhecimentos, autonomia, articulação do desenvolvimento pessoal e profissional, contribuindo para que o sujeito se torne "autor de suas práticas".

Em PenseSUS e as redes sociais: a busca por estratégias de comunicação e os desafios para a democratização e descentralização do debate sobre o SUS, Cavalcante et al. ${ }^{15}$ oferecem o relato de uma experiência que buscou ter como referência os princípios do SUS para dinamizar as suas próprias estratégias de comunicação. O texto não oferece respostas, antes problematiza alguns dos muitos aspectos envolvidos, aponta o entrecruzamento de distintas lógicas e contextos, as quais pouco conhecemos, juntos ou em separado. São muitas as perguntas das autoras e uma delas merece atenção redobrada, dado o investimento nas redes sociais: quais os parâmetros que devem avaliar o êxito ou não das iniciativas que buscam alargar o debate e a visibilidade sobre o SUS e seus sujeitos no ciberespaço?

Caro(a) leitor(a), como se pôde ver, são muitos os temas e as questões que a Revista Brasileira de Pesquisa em Saúde coloca à sua disposição. Espero que sua própria leitura traga outras conexões, interesses, perguntas e caminhos que estreitem ainda mais os vínculos entre os direitos à saúde e à comunicação, decisivos para o real exercício da cidadania no país. Boa leitura!

\section{REFERÊNCIAS |}

1. Cavalcante C, Lerner K. Duas faces do mesmo Sistema? Um estudo dos sentidos do Sistema Único de Saúde no jornal Diário do Nordeste. Rev. Bras. Pesq. Saúde, Vitória, 20(2): 25-34, abr-jun, 2018.

2. Silva-Mascarelo T, et al. A saúde e o Sistema Único de Saúde nos bastidores da imprensa: o que os jornalistas têm a nos dizer?,Rev. Bras. Pesq. Saúde, Vitória, 20(2): 64-73, abr-jun, 2018.

6| Rev. Bras. Pesq. Saúde, Vitória, 20(2): 4-7, abr-jun, 2018 
3. Novaes JPA, et al. Análise qualitativa de notícias veiculadas na mídia impressa sobre dieta alimentar e saúde bucal, Rev. Bras. Pesq. Saúde, Vitória, 20(2): 8-15, abr-jun, 2018.

4. Villela EFM. Sintomas, tratamento e diagnóstico: a dengue na mídia impressa durante primeira epidemia em Ribeirão Preto, São Paulo. Rev. Bras. Pesq. Saúde, Vitória, 20(2): 121-128, abr-jun, 2018.

5. Tavares FL, et al. Ciclismo e saúde: as matérias sobre bicicleta veiculadas em um jornal de grande circulação no Espírito Santo. Rev. Bras. Pesq. Saúde, Vitória, 20(2): 88-97, abr-jun, 2018.

6. Emerich TB, et al. O jornal Folha de S. Paulo no contexto das indústrias culturais e midiáticas: um olhar para as manchetes sobre o Programa Mais Médico. Rev. Bras. Pesq. Saúde, Vitória, 20(2): 16-24, abr-jun, 2018.

7. Coqueiro JM, et al. Diabetes mellitus na mídia impressa: uma proposta de protocolo de coleta e classificação de dados para pesquisa.Rev. Bras. Pesq. Saúde, Vitória, 20(2): 74-87, abr-jun, 2018.

8. Cavaca SD, et al. Observatório de Saúde na Mídia -Regional Espírito Santo: relato de uma experiência interdisciplinar em Saúde Coletiva. Rev. Bras. Pesq. Saúde, Vitória, 20(2): 149-156, abr-jun, 2018.

9. Nacif MA, Emmerich AO, Rebouças E. Zika e publicidade: reflexões sobre comunicação de risco e emergência em saúde na perspectiva das Indústrias Culturais e Midiáticas. Rev. Bras. Pesq. Saúde, Vitória, 20(2): 110-120, abr-jun, 2018.

10. Barros IS, et al. Alimentação saudável na mídia de massa e promoção da saúde: percepções sociais de Agentes Comunitários.Rev. Bras. Pesq. Saúde, Vitória, 20(2): 35-43, abr-jun, 2018.

11. Trindade D, Spinielli MA, Moreira B. Modelos da Comunicação no Processo de Humanização do Parto e Nascimento em uma Maternidade de Mato Grosso. Rev. Bras. Pesq. Saúde, Vitória, 20(2): 44-53, abr-jun, 2018.

12. Santos MSO, Gurgel IGD, Augusto LGS. Documentário e cinedebate como estratégia de pesquisa-ação em saúde: comunicando perigos, construindo saberes, promovendo saúde. Rev. Bras. Pesq. Saúde, Vitória, 20(2): 129-139, abr-jun, 2018.

13. Souza APV, Rocha CF.Comunicação e saúde: abordagens e experiências da TV Ufes. Rev. Bras. Pesq. Saúde, Vitória, 20(2): 98-109, abr-jun, 2018.

14. Costa MA, et al. O portfólio na formação em saúde: limites e possibilidades em uma experiência de educação à distância. Rev. Bras. Pesq. Saúde, Vitória, 20(2): 54-63, abr-jun, 2018.

15. Cavalcante CC, et al. PenseSUS e as redes sociais: a busca por estratégias de comunicação e os desafios para a democratização e descentralização do debate sobre o SUS. Rev. Bras. Pesq. Saúde, Vitória, 20(2): 140-148, abr-jun, 2018. 